\title{
Audiência infantil de programas policiais: uma abordagem reflexiva
}

\author{
Mirna Albuquerque Frota ${ }^{1}$ \\ Ceci Vilar Noronha ${ }^{2}$ \\ Caroline Soares $\mathrm{Nobre}^{3}$ \\ Jessica de Lima Aquino Nogueira ${ }^{4}$ \\ Luiza Luana de Araújo Lira Bezerra ${ }^{5}$
}

Objetivou-se averiguar a formação familiar e a permissibilidade dos pais sobre os programas policiais de televisão para crianças. Estudo exploratório descritivo de natureza qualitativa, durante março a outubro de 2008. Os participantes foram 15 crianças do ensino fundamental em Fortaleza - Ceará - Brasil. A coleta de dados foi por meio de entrevista semi-estruturada. Após a análise, emergiram categorias: A estrutura familiar como formulador de valores, Audiência infantil nos programas policiais, Percepções das crianças em relação à influência dos pais. Conclui-se que não há qualquer controle intrafamiliar contra a participação ou a presença das crianças ao assistir a programas com conteúdos violentos.

Descritores: Criança, Relações familiares, Violência Doméstica, Saúde Pública.

\section{Child audience of cop shows: a reflective approach}

This study aimed to investigate the family background and the permissibility of parents concerning police television programs for children. This exploratory, qualitative, descriptive study was carried out from March to October 2008. The participants were 15 children who attend elementary school in Fortaleza Ceará - Brazil. For data collection, it was used semi-structured interviews. After an analysis, three categories emerged: Family structure as a creator of values, Child audience of cop shows, and Children's perception about the influence of their parents. It was concluded that there is no control within the family against the idea of children watching TV shows that contain violence.

Descriptors: Children, Family relationships, Domestic Violence, Public Health.

\section{La audiencia infantil de programas policiales: un enfoque reflexivo}

Se objetivó determinar la formación familiar y la permisibilidad de los padres sobre los programas policiales de televisión para los niños. Estudio cualitativo, exploratorio y descriptivo, realizado de marzo a octubre de 2008. Los participantes fueron 15 niños de la escuela primaria en Fortaleza - Ceará - Brasil. La recolección de datos fue a través de entrevistas semi-estructuradas. Después de un análisis, tres categorías emergieron: La estructura familiar como formuladora de valores, Audiencia infantil de programas policiales, y Percepciones de los niños en relación a la influencia de los padres. Se concluyó que no existe un control dentro de la familia en contra de la presencia o participación de niños en ver programas con contenido violento.

Descriptores: Niños, Relaciones Familiares, Violencia Doméstica, Salud Pública.

\section{INTRODUÇÃO}

A s dimensões da violência apresentam-se como temas abordados na mídia, o que propõe à sociedade no âmbito familiar, ideias diversas quanto sobre a origem e controle do ato. Diante dessa preocupação, evidencia--se um problema social grave, no qual se acrescenta a veemência na saúde coletiva ao perceber resultados gerados por este fenômeno.

Diante da dificuldade para se conceituar violência, adota-se a definição como um fenômeno de ordem vivido, cujas manifestações provocam ou são provocadas por uma forte carga emocional de quem a comete, de quem a sofre e de quem a presencia. Portanto, para compreender a dinâmica da realidade brasileira, é válida a pausa frente à visão que a sociedade projeta, seja por meio da filosofia popular, seja do ponto de vista erudito(1).

Discutida e abordada nos diversos segmentos da sociedade moderna, de modo a envolver os aspectos sociais, culturais, as diferenças de sexo e raça, as hegemonias e suas minorias, revelam o cotidiano da individualidade das relações pessoais. Logo, conhecer as características da família e detectar as formas de violência que estão implícitas nas atitudes e posturas de cada membro requer uma avaliação minuciosa da comunicação verbal e não verbal de cada indivíduo (2).

Os meios de comunicação são processos institucionalizados, cujo sentido das mensagens não é estabelecido de forma

1 Enfermeira. Doutora em Enfermagem. Docente do Mestrado em Saúde Coletiva e da Graduação em Enfermagem da Universidade de Fortaleza - UNIFOR. Líder do Grupo de Pesquisa e Estudo em Saúde da Criança - NUPESC/CNPq/UNIFOR. Email: Mirnafrota@unifor.br

2 Enfermeira. Doutora em Saúde Pública. Professora Adjunta do Instituto de Saúde Coletiva, Universidade Federal da Bahia/UFBA

3 Enfermeira. Mestranda em Saúde Coletiva da Universidade de Fortaleza - UNIFOR. Participante do Grupo de Pesquisa e Estudo em Saúde da Criança - NUPESC/CNPq/UNIFOR

4 Enfermeira. Atua no Hospital Geral de Fortaleza - HGF.

5 Enfermeira. Mestranda em Saúde Pública da Universidade Estadual do Ceará - UECE. 
unidirecional - da mídia para o público -, mas na relação entre o universo particular do sujeito e os produtos. De modo que o receptor não é passivo às ideias abordadas, mas participa da produção de uma lógica cultural própria, assim como lida com possibilidades na construção de significados ${ }^{(3)}$.

A tecnologia e a facilidade das redes interligadas possibilitam o acesso de todas as faixas etárias a qualquer tipo de informação, portanto, a criança está em posição vulnerável, em período de formação da personalidade e absorção de conhecimento na qual Abramovay ${ }^{(4)}$ expõe esta situação como possível de manifestar em um plano estrutural, e no plano, mas subjetivo pelo desenvolvimento dos sentidos e incerteza e insegurança entre eles.

A autonomia do telespectador frente ao conteúdo abordado pela mídia é praticamente inexistente. Além das contradições e ambiguidades que atravessam os meios de comunicação, existem sujeitos inteligentes, capazes de dialogar com os enunciados que lhes são dirigidos, e de refletir, com diferentes níveis de criticidade, a respeito do conteúdo e do significado das mensagens a que têm acesso(3).

Com o intuito de formular uma atenção diferenciada e minimizar as inúmeras causas/tipos de violência, na qual a criança é acometida, objetivou-se averiguar a formação familiar e a permissibilidade dos pais sob os programas policiais de televisão para as crianças.

\section{METODOLOGIA}

Em decorrência do grau de complexidade e subjetividade do objeto de estudo, optou-se em trabalhar a abordagem qualitativa que utiliza o universo de significados, motivos, aspirações, crenças, valores e atitudes, que corresponde a um espaço profundo das relações dos processos e dos fenômenos ${ }^{(5)}$. Trata-se de uma pesquisa do tipo exploratória descritiva, que evidencia os sujeitos no contexto social.

Durante a observação não participante no cenário do estudo, foi possível identificar crianças que assistiam a programas policiais televisivos, sendo estas caracterizadas como informantes do estudo. Participaram 15 sujeitos, alunos do ensino fundamental, de ambos os sexos entre 8 e 12 anos, de acordo com o Estatuto da Criança e do Adolescente ${ }^{(6)}$ que considera criança o indivíduo de 0 a 12 anos incompletos.

$\mathrm{O}$ número de participantes justifica-se com base na representatividade qualitativa defendida por Thiollent ${ }^{(7)}$, pois trata de um grupo com poucas pessoas, escolhidas de forma intencional em função da relação que detêm com o assunto abordado pelo estudo.

A pesquisa foi desenvolvida em uma Escola de Ensino Fundamental e Médio, situada na periferia da cidade de Fortaleza/CE, localizada em uma área onde são crescentes os índices de violência, sobretudo contra a criança, no período de março a outubro de 2008.

Os métodos utilizados para a coleta de dados foram a observação livre e a entrevista semiestruturada em forma de narrativa, com as questões norteadoras: Quem mora com você? Qual o programa que você mais assiste? As crianças foram convidadas e a partir da predisposição dos mesmas foram agendadas as entrevistas.

Os dados foram agrupados por meio da temática de Minayo ${ }^{(5)}$, cujo método caracteriza-se pela descrição e documentação dos relatos. Em seguida, ocorreu a categorização das falas e posteriormente a descoberta da saturação de ideias e os significados similares e diferentes; por último a síntese do pensamento e a interpretação dos achados.

Os aspectos éticos e legais de pesquisas envolvendo seres humanos, conforme a Resolução196/96 ${ }^{(8)}$, foram seguidos e observados. O estudo foi submetido e aprovado pelo Comitê de Ética em Pesquisa da Universidade de Fortaleza - UNIFOR, sob Parecer $n^{\circ} 162 / 2006$. Os pais e responsáveis assinaram o Termo de Consentimento Livre Esclarecido (TCLE), assegurando-se o anonimato e o respeito à decisão de não participar ou de desistir a qualquer momento do processo.

\section{RESULTADOS E DISCUSSÃO}

Conhecer o cotidiano infantil susceptível à violência pode ser considerado um dos pilares a minimizar a situação da segurança pública. Assim como na descoberta dos modos de viver em harmonia, em formação segura e por meio do desenvolvimento saudável evidenciados nos relatos emergiram as categorias temáticas.

\section{Audiência infantil nos programas policiais}

Observou-se a intensa participação dos infantes como telespectadores dos programas policiais. Os atos violentos mais graves, como os praticados com alinhos de crueldade, são vistos por alguns setores da mídia e da opinião pública como meio de alcançar a "massa" (população) e aumentar a audiência. Assim, os de tendências cruéis, resultado da maldade inerente à natureza humana, chegam aos domicílios sem qualquer controle de visual, facilitando o acesso de jovens ao conhecimento perspicaz da sociedade.

É nesse aspecto que se discute a precisão do aconselhamento dos responsáveis quanto ao conteúdo negativo abordado na televisão, que faz emergir para as crianças, a naturalidade e a rotina de atos violentos, de modo a proporcionar uma realidade banalizada pela agressividade, não ocorrendo uma consciência crítica em relação a influência negativa para a vida social.

"Assisto Cidade 190, o Barra Pesada e só às vezes o Linha Direta, mas não é muito não, porque passa muita gente morta de faca, de bala e até de pedra." (C1)

"Eu assisto só de vez em quando o Barra Pesada, porque passa muita coisa ruim. Teve uma vez que passou um homem todo furado de bala por causa de uma briga com o pai dele. Foi feio demais, tinha muita gente olhando." (C2)

Não há um consenso em relação ao impacto da mídia sobre as crianças, ressaltando que, na concepção norteamericana, o tempo despendido diante da televisão e na recepção de cenas de violência, as mesmas ficam vulneráveis a seu conteúdo, aoqual são associados ao desenvolvimento de comportamentos agressivos por parte dos infantes ${ }^{(9)}$. As crianças citam programas policiais exibidos nos canais abertos 
em horários de grande audiência e, por isso, descrevem quase que detalhadamente as reportagens que atraíram sua atenção.

Em sua pesquisa, Magalhães ${ }^{(10)}$ nota o fascínio que esse tipo de programa e notícia exerce sobre os pesquisados. Revela que a televisão trabalha com uma visão única sobre a violência, apresentando-a como drama e como espetáculo, que tem ápice na tragédia. Completa, ao expor, que há uma suposição de que a mídia cria comportamentos violentos e ensina aos jovens, principalmente os vulneráveis, a cometerem crimes.

"O Cidade 190, porque passa muita notícia ruim, aí pode passar alguém da nossa família lá e a gente nem fica sabendo, uma vez passou até o meu primo que morreu por causa de briga de gangue, a gente só soube porque eu vi primeiro na reportagem."(C4)

"É só o que assisto nas minhas férias é o Barra Pesada, eu acho é bom ver gente morta porque arruma confusão com os outros e morre." (C5)

"Eu assisto o Rota 22 e o Comando 22, mas tenho medo. Às vezes, o povo mata os outros de paulada e tinha um monte de pedaço da pessoa no chão, dava pra ver até o cérebro." (C6)

A exposição intensiva às notícias de fatos ditos violentos, que cobrem um amplo espectro de situações diferentes, reforça na população em geral a ideia de que a violência está banalizada no País e de que há pouco a fazer para modificar a relação vivenciada pelos indivíduos envolvidos, dada a insuficiência e ineficácia das medidas tomadas pelos poderes públicos. A imprevisibilidade das ações violentas e a crescente consciência da impotência geram no imaginário coletivo e individual a representação da violência como força cega e incontrolável(11).

\section{Estrutura familiar como formulador de valores}

As crianças conceituaram a família como aos que junto com ela ocupam uma casa, que se resume à mãe ou ao pai e irmãos. $E_{\text {, }}$ em muitos casos a responsabilidade sobre o infante pode ser delegada a uma pessoa com outro grau de parentesco, ou até nenhum.

Independente da estrutura familiar, ou seja, em seu modelo próprio e singular, pode experimentar mudanças de vida ou eventos inesperados, que acarretam a necessidade da obtenção de suporte social/familiar, que entre as suas definições, existe um consenso a respeito do papel da família como fonte segura de apoio, assim, o mesmo deve ser analisado de forma ampla, visando considerar todas as relações significativas dessa

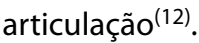

"Minha mãe (adotiva), meu padrasto e meu irmão (2 anos). A minha mãe de verdade mora na Itália, mas de vez em quando ela aparece pra me ver. Eu não sei quem é meu pai, porque quando minha mãe se separou eu ainda ia nascer." (C5)

"Meu tio, minha avó, minha mãe e o meu irmão (8 anos). Meus pais se separaram, e o meu irmão mais novo, de 3 anos, mora com o meu pai." (C14)

"Pai, minha avó, minha prima e meus irmãos (16 anos e 11 anos). Meus pais são separados, e minha mãe saiu de casa para se juntar com uma mulher." (C10)

A família remete um sentido único para o individuo, que, como ser biopsicossocial, integra a cultura e o seu grupo social, o que leva a se estudar a família de modo contextualizado, considerando a subjetividade de cada ser. Mais do que isso, a família exerce uma ação determinante na educação, pois é nesse espaço que são submergidos os valores éticos e morais. É igualmente em seu interior que se moldam as marcas entre gerações e são observados valores culturais ${ }^{(13)}$.

A ideia de um conceito que denota subjetividade, referindo-se a um perceber próprio, sobre a condição de vida e valores, com influência do meio, quando este é viável, a boa educação, e, portanto proporcionando a inexistência de violência ${ }^{(14)}$. A família quando constituída por pai biológico, mãe biológica e filhos não representa a estabilidade psicoemocional, muitas vezes pela distância que desarmoniza os componentes. Assim, o bom desenvolvimento é comprometido por desentendimentos.

"Eles brigam, porque quando a minha mãe vai pra igreja comigo, eu fico chamando meu pai pra ir, aí a mãe se mete $e$ eles começam a brigar." (C16)

"A minha mãe briga muito com o pai, porque ele vive traindo ela." (C17)

"Minha mãe e meu pai brigam por causa dos meus irmãos, das coisas ruins que eles fazem." (C19)

As condições e circunstâncias de desestrutura social e familiar podem provocar um caráter eminentemente humano da violência - sobretudo na juventude bombardeada pelos apelos de consumo e falta de reconhecimento e de chances sociais -que constroe as taxas de criminalidade e as consequências da violência(1). Logo, as crianças são os principais alvos desse comportamento, pois aprendem no lar como "proceder" diante da sociedade.

\section{Percepção da criança em relação à influência dos pais}

A sociedade brasileira está institucionalizada pela violência, em que as crianças convivem em um âmbito caótico ao se banalizar os atos violentos pela mídia. Dentro dessa concepção, devem-se utilizar instrumentos que resgatem o diálogo familiar, o respeito à infância dentro e fora do domicilio. $O$ momento é de alerta e comum a todos os cidadãos.

"Eu assisto esses programas porque passa notícia. Minha mãe não diz pra não assistir, ela até corre pra ver quando tem alguém morto." (C2)

"Assisto todo dia, porque a gente sabe das coisas que acontecem de ruim em todo canto. O povo lá de casa dá valor assistir também [...]" (C6)

Os infantes referem assistir a programas policiais por seus pais não se oporem ao conteúdo transmitido ou até fazerem parte da "plateia". Esse entretenimento é contemplado no horário em que parte da família encontra-se reunida, pois consideram o programa como informativo e noticiário.

$\mathrm{O}$ interesse despertado pelos programas policiais faz parte da vida e o conteúdo violento é visto de forma habitual pelos pequenos espectadores. A situação torna-se grave por tais representações serem acessadas de maneira simples. Não se trata de demonizar a mídia, uma vez que esta faz eco a uma sociedade que, cada vez mais, espelha uma "banalização do humano" em 
tudo aquilo que diz respeito à manutenção dos laços sociais ${ }^{(15)}$.

A criança, em sua naturalidade, possui uma maneira de pensar, sentir e reagir, e é capaz de fazer escolhas, tomar decisões, encontrar soluções e assumir responsabilidades. Enfim, a mesma deve ser respeitada e individualizada pelas especificidades e necessita de condições favoráveis ao crescimento e desenvolvimento, tais como: convivência familiar, ambiente seguro e educação(16).

"Eu assisto é muito, a minha mãe diz que é feio a pessoa não assistir porque aí não vê o que tem de ruim no mundo." (C9)

"Eu assisto porque meu pai disse que não tem nada a ver a criança não poder assistir essas coisas, tem que assistir pra quando crescer não ter medo de nada." (C10)

Os fenômenos da violência, ao serem enfocados pelos meios de comunicação, invadem cotidianamente os sentidos com espetáculos que parecem transparecer a realidade da sociedade. São imagens, discursos e narrativas que provocam deslocamento nos conteúdos do imaginário social, com um quadro mental de intranquilidade e de caos, apreendido como representativos da contemporaneidade brasileira ${ }^{(17)}$.

As narrativas demonstram a permissibilidade do acesso aos programas policiais, sendo complacente àquelas que moram em bairros carentes, pois estão atreladas e visualizam sua realidade nas reportagens abordadas, o que pode vir a comprometer o desenvolvimento emocional, social, e suas relações para com a comunidade.

\section{CONSIDERAÇÕES FINAIS}

O ambiente em que o infante se desenvolve é a base para sua formação. Assim, absorve de maneira natural costumes adotados. Ao relacionar a infância e os programas policiais, revela-se a necessidade de compreender os valores familiares, de modo a analisar o acesso à mídia, e consequentemente refletir a interface entre os programas e o contexto da educação.

Evidencia-se a análise crítica da infância contemporânea e sua relação com a televisão para reformulação dos programas policiais exibidos para o público infantil. Inexiste acompanhamento intrafamiliar diante da presença da criança na exibição de programas com conteúdos violentos. Ressalta-se a naturalidade como estes atos são visualizados, pois são transmitidos como parte da vida cotidiana.

As imagens das reportagens vistas nos domicílios são aprimoradas nas ruas. A preocupação que outras gerações demonstravam são banalizadas, classificando a sociedade como "imune" a qualquer notícia que envolva atos inimagináveis para a capacidade do ser humano.

\section{Referências}

1. Minayo MCS. Violência e saúde. Rio de Janeiro: Fiocruz; 2006.

2. Medina ABC, Penna LHG. A percepção de enfermeiras obstétricas

acerca da violência intrafamiliar em mulheres grávidas [Internet]. [citado

2009 Mar 01]. Disponível em: http://www.scielo.br/scielo.php?script=sci_

arttext\&pid=S0104-07072008000300007\&lng=pt. doi: 10.1590/S0104-

07072008000300007

3. Duarte R, Leite C, Migliora R. Crianças e televisão: o que elas pensam

sobre o que aprendem com a tevê [Internet]. [citado 2012 Jul]. Disponível

em: http://www.scielo.br/scielo.php?script=sci_arttext\&pid=S1413-

$24782006000300010 \&$ lng $=$ pt\&nrm=iso.

4. Ministério da Saúde (BR). Secretaria de Vigilância em saúde. Impacto da violência na saúde dos brasileiros. Brasília: Ministério da Saúde; 2005.

5. Minayo MCS. O desafio do conhecimento: pesquisa qualitativa em saúde.

$12^{2}$ ed. São Paulo: Hucitec; 2010.

6. Brasil. Lei no 8.069 , de 13 de julho de 1990. Estatuto da Criança e do

Adolescente. Brasília: CBIA; 1990.

7. Thiollent M. Metodologia da pesquisa ação. 12a ed. São Paulo: Cortez; 2003.

8. Ministério da Saúde (BR). Conselho Nacional de Saúde, Comissão Nacional

de Ética em Pesquisa. Resolução № 196 de 10 de outubro de 1996: aprova

as diretrizes e normas regulamentadoras de pesquisa envolvendo seres

humanos. Brasília: Ministério da Saúde; 1996.

9. Magalhães N. Significados de violência em abordagens da mensagem televisiva. Sociologias. 2009;11(21):318-43.

10. UNICEF- Fundo das Nações Unidas para a Infância Violência na Mídia

[Internet]. [citado 2012 Ago]. Disponível em: http://www.unicef.org/brazil/pt/ Cap_04.pdf

11. Pino A. Violência, educação e sociedade: um olhar sobre o Brasil

contemporâneo [Internet]. [citado 2008 Mar]. Disponível em: http://www.

scielo.br/scielo.php?script=sci_arttext\&pid=S0101-73302007000300007\&lng $=$ pt\&nrm=iso. doi: 10.1590/S0101-73302007000300007

12. Mombelli MA, Costa JB, Marcon SS, Moura CB. Estrutura e suporte familiar como fatores de risco de stress infantil. Estud Psicol. 2011;28(3):327-35.

13. Gomes MA, Pereira MLD. Família em situação de vulnerabilidade social: uma questão de políticas públicas. Ciênc Saúde Coletiva. 2005;10(2):357-63.

14. Martins E. Programa de educação para saúde como recurso para melhoria de conceitos relacionados à qualidade de vida [dissertação]. São Paulo:

Universidade Presbiteriana Mackenzie de São Paulo; 2000.

15. Vilhena J, Bittencourt MIGF, Zamora MH, Novaes JV, Bonato MCR. Medos infantis, cidade e violência: expressões em diferentes classes sociais. Psic Clin. 2011;23(2):171-86.

16. Santos LES, Resck ZMR, Carneiro VG. A creche e o contexto social.

Nursing (São Paulo). 2003;59(6).

17. Porto MSG. Mídia, segurança pública e representações sociais. Tempo

social. Rev Sociol USP. 2009;21(2):211-33 